Stewart Pearson is president and chief operating officer of FCB Direct Worldwide
Keywords: Brand, Customer Relationship Marketing, loyalty, innovation, investment

'The people who live in the past must yield to the people who live in the future.'

Arnold Bennett

'A frog placed in a pan of water will not leap out if the water is gradually heated, even to the point where the frog eventually boils to death.'

Ancient Chinese proverb

Stewart Pearson

Chief Operating Officer, FCB Direct Worldwide, 150 East 42nd Street, New York NY 10017-5612 USA

Tel: +1 2128853370

Fax: +1 2128853094

E-mail: spearson@fcb.com

\section{The real challenge of being direct: A strategic and operational road map for customer relationship marketing}

\author{
Stewart Pearson \\ Date received (in revised form): 18 August 1999
}

\begin{abstract}
This article looks the consequences for the traditional organisation of the final victory of direct methodology, powered by the new technology. The author asserts that the keys to the future lie in the primacy of Information, in Innovation of process rather than merely product, and in Interactivity with customers. Using these keys to unlock the future will demand a revolution in company organisation, based on the customer, not the product, as the unit of value.
\end{abstract}

\section{Introduction}

Today what we know as direct marketing is poised to become the new mainstream global business model. Businesses must redefine themselves in terms of the customers they serve and not the products they manufacture or distribute. For management determined to win in the new economy the real challenge is speed and performance of operations and process, not strategy.

Exaggerations, surely? The products of a career direct marketer's fevered imagination?

The direct model has already won in many categories, from financial services to personal computers, from supermarkets to auction houses. Who would you rather be? Barclaycard or Capital One? Compaq or Dell? Sainsbury's or Tesco? Butterfields or eBay?

Capital One has an information-driven business model that mass customises propositions and prices to deliver value that is superior because tailored. Cap One is now targeting the UK market, yet a senior executive at the most profitable British banking group dismisses the challenge of 'American direct mailers' against his established brand. He will find barriers to entry low, brand loyalty no defence against superior value tailored to individual needs - and his most profitable customers the first targets and defectors.

Compaq's manufacturing prowess and distribution clout cannot match the 'best customer experience' delivered seamlessly by Dell. Compaq strives to reach every customer by supporting a growing re-seller network and acquiring the Digital salesforce. Dell uses the most effective and efficient direct response marketing in the world to motivate customers to call its service, access its website and buy 
Pearson

\section{The purpose of loyalty cards}

\section{Cars, segmentation and services}

immediately - directly from advertising. The mountain has come to Mohammed. Customers reach to Dell, not the other way around. Real-time marketing is as vital to Dell's competitive advantage as zero-inventory manufacturing, a reality few 'get'.

Sainsbury's certainly does not 'get' the point of the loyalty card pioneered by Tesco, and has been overtaken in market share and profitability. The point is not the promise of rewards, but the exchange of information. Sainsbury's misses the true business advantages of so-called loyalty programmes. Retailers must learn to leverage information to target effectively and market diversified services. Longer term they will exploit closer knowledge of and relationships with selected customers to go completely direct and provide home-shopping solutions.

Like so many of the dot.coms, online auction site eBay faces the challenge of building a brand quickly. But today investors are important stakeholders, and a brand can be developed in the financial as well as the consumer market. So part of the answer to eBay's challenge is to acquire the established and venerable brand of Butterfields, a potential win-win for both sets of investors.

The race is on to excel at direct, database, interactive and relationship marketing. Which categories are up next for the duel between the past and the future, the business models of yesterday and tomorrow? Watch car manufacturers, food brands, telecommunications providers and entertainment producers. Ask who is living in the future. Which frogs will leap for safety? BMW or Ford? P\&G or Kraft? MCI or AT\&T? Sony or Disney?

Ford is pursuing two new strategies, segmentation and services, radical for a volume car manufacturer. Several years ago Ford considered customer instead of product and faced a discomfiting reality. There are at least 17 distinctive consumer segments for cars, and although supposedly a mass-market manufacturer, Ford was a serious competitor in only four of them. Now Ford tailors new models like the Ka in Europe for younger, growing segments. And it acquires and integrates brands like Jaguar and Volvo to serve older, affluent segments.

Further, for customers in all the segments in which it chooses to compete, Ford wants to offer the customer more. It wants to meet the customer's need, in Yankelovitch language, for 'right-hand' brands on which customers depend to manage their lives. Ford wants to be an automotive service company rather than a maker of cars. The first steps are to acquire Kwik Fit for repair services, develop the Ford credit business, and find partners to offer tailored financial services to Ford drivers.

While P\&G hogs headlines with its undeniably far-seeing initiatives in digital media, Kraft is quietly learning how to identify its most valuable customers and develop more profitable relationships with them at all points of interaction (of which the Internet is only one). A major challenge is to offer more value in-store, where the retailer must become ally not adversary, and where technology enables targeted offers and higher service levels.

MCI, now MCI Worldcom, continues to attack AT\&T's long-distance business with aggressive price propositions, most recently with a 


\section{Cannibalise yesterday's revenue}

\section{Re-invent the organisation}

five-cents-per-minute rate. But voice telephony is the past, has a tiny marginal cost of supply and is moving quickly to a free-service model. Profit must result from relationships with valuable customers and bundled added-value services.

Rather than defending the indefensible, AT\&T is looking to the future for new revenue streams from cable, Internet and still-unimagined new services, all delivered through broadband connections into the home. This will purposefully cannibalise yesterday's revenue to create tomorrow's.

While Sony continues to struggle for synergy among its diverse product portfolios and consumer franchises, Disney reorganises to combine all its Internet holdings under one business unit. Cross-selling is an unfulfilled strategy in many industries, but on the Web the opportunity to learn preferences and build profiles quickly enables marketers to serve up new propositions proactively from any part of a portfolio or any combination of products and services. For Disney as for others, the Web demands a new architecture to enable the consumer to gain access to all parts of the organisation.

The new economy demands a new strategic framework, to navigate this complexity and manage the business from a customer rather than a product perspective. But the real challenge is operational. To compete on the new terms, people and organisations must change. To deliver to customer needs we must all reinvent our businesses around a new organisation and new, quality, rapid processes.

The author's conviction is that the essential business model for the new economy is well understood. It is direct, database, interactive, relationship marketing. We have a new articulation in the form of CRM, customer relationship marketing, but we all know what we mean. The marketing and advertising communities embrace integrated communications and switch resources to targeted communications and customer service, and we all know that we are at last putting the customer first. The financial markets value stocks, especially the dot.coms, on the basis of traffic, eyeballs and future customer revenues, and we all know that they are projecting potential lifetime value. So in setting out the strategic model below the author does not make any claim for unique insight.

But few companies have yet learned to organise for CRM, change the pace at which they operate, and partner with and learn from customers. Most challenging, few have yet gathered the courage to become fully accountable for their investments, or create an open culture in which management accepts feedback from customers and readily responds to change. As well as new processes a new style is demanded, bottom-up rather than top-down.

Complementing the strategic with an operational model is thus a means of addressing the real challenge of 'being direct': to change a real-world organisation and its processes from a product to a customer basis. 
Information is the driving force

\section{The customer compass}

\section{The strategic model}

There are four stages in CRM strategy: plan for growth by accountable investment in customer segments with future potential; create innovative value for customers through superior process; build compelling brands through intimate relationships with customers; go to market through consistent and coherent interaction with customers, and measure their response, across all media, channels and touch points.

How is this different from traditional marketing? The driver of strategy is not brand. Nor is it the Internet. The driver is information.

Armed with customer information the role of marketing moves upstream, right to the boardroom and the major strategic questions confronting management and determining investment. Typically the role of marketing has been to manage communication, the 'go to market' aspect of operations. Now marketing must use customer information to drive the presentation of the business in the form of the brand, the value proposition on which the business will compete and the allocation of investment in all aspects of the business's operations.

The Internet is important. On the Internet the CRM process is turbocharged, and strategy guides operations in real time. In the digital world the customer compass operates on the fly, creating competitive value, building relationships and directing interaction with customers as they search and transact on the Web.

But although important, the Internet is only one of many touch points with customers. Wherever, whenever and however an organisation interacts with customers, it can quickly learn what works and why. It can adopt the learning to generate continuous improvement. The Japanese manufacturing concept of kaizen can be applied to marketing, which like manufacturing can be tasked with the achievement of measurable productivity gains.

The customer compass is not a direct marketing tool. Neither is it just for marketers. The case is not simply that all marketing is direct, but

Figure 1: The customer compass

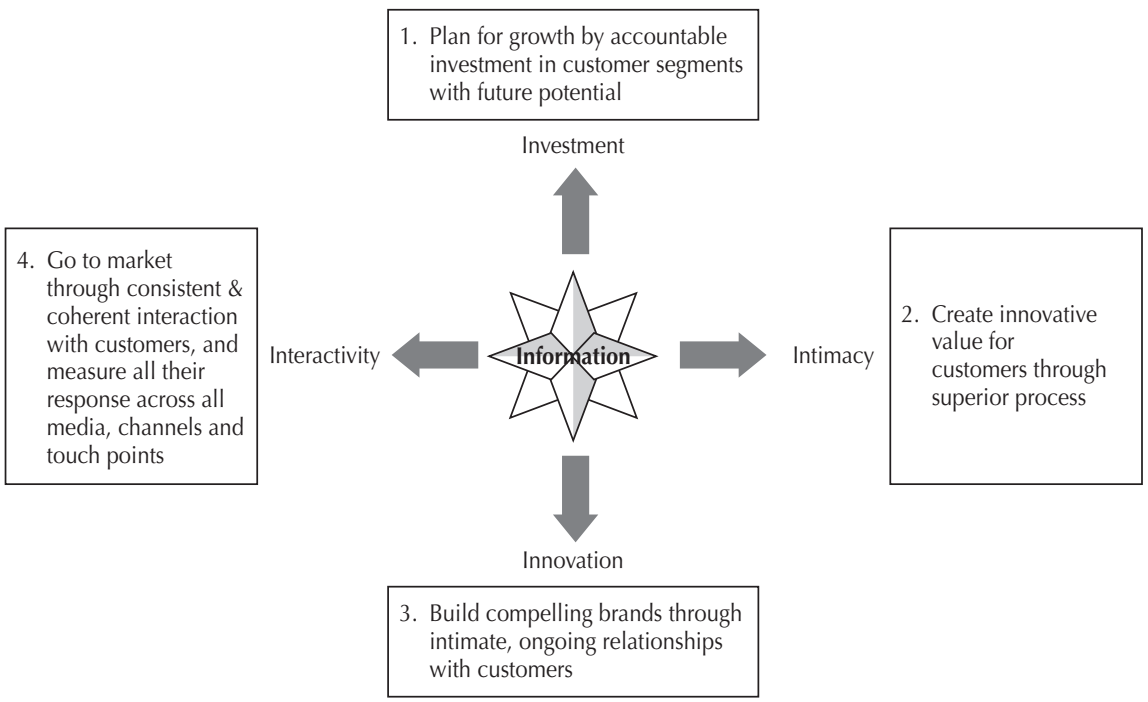


rather all business is marketing and all marketing is customer development or CRM. This is not an original idea. As Peter Drucker put it over 40 years ago:

\section{'There is only one valid definition of business purpose: to create a customer ... because of its purpose to create a customer, any business has two - and only two - basic functions: marketing and innovation.'}

The four stages of a CRM strategy are not sequential, They are determined and executed simultaneously. But, pace Drucker, the right conceptual starting point is business purpose and 'investment', closely followed by the value proposition and 'innovation'.

\section{Investment}

To operate CRM asks a business to make a huge leap, from its product past to its customer future. How we define and account for a business can no longer be based on the products made but on the customers served.

If we define a business in terms of its customers and not its products, we must certainly do the numbers, the accounts and the profit and loss, on this basis. The unit of value is the customer relationship and not the

\section{Customers, not products, as the accounting unit} product sale. Analysis of information drives the identification of customer segments with future potential, the projection of the investments required to realise that potential, and the returns on these investments. Most companies simply do not do this analysis. They rely on demographics and attitudes. They need to analyse behaviour, focus on financial value and predict future sales rather than past results. And they need a customer database to operate CRM and apply the analysis.

The author used to write that, with a customer perspective and return on investment methodology, marketing can compete with manufacturing and other functions for long-term investment. In fact there is a deeper advantage in customer accounting. All functions can invest against customer potential, exactly as it should be when customers are central and marketing is everything.

If someone in the organisation is responsible not for a product or function, but for a customer, investment strategy identifies target customer segments, calculates investments and projects returns on investments to determine business and marketing priorities. Rapid growth is not limited to capital investment or acquisition: growth can be planned confidently from calculated investment in valuable customers as well as in fixed stock or new businesses.

\section{Innovation}

Change is the constant, competition is intense and customer needs never stand still. To sustain a competitive advantage in the global market demands continuous innovation in value. To secure for a brand a unique and continuing role in a customer's life means that distinctive experiences must be designed to deliver value. And the critical success factor in the creation of distinctive experiences is speed and performance of process. 
Pearson

\section{Innovation is process as well as product}

The personal computer market is a perfect illustration of how value demands innovation, in process as in product. Competition was formerly based on manufacturing, the ability to deliver the most power at the least price. Compaq became the market leader as a direct consequence of being the low-cost quality manufacturer. Its existence now under threat from the direct model, Compaq is no less effective as a PC manufacturer and continues to bring new technologies to a broad market affordably. But Compaq's process for interacting with customers - how it communicates, distributes and responds to them - is no longer competitive.

Compaq can manufacture to meet customer needs but its business model fails in two critical ways: speed and performance. It cannot assess and respond to customer needs fast enough. And it cannot meet customer needs for personalised service and support because it is distant from the buyer. Compaq has yet to master direct.

Dell is the master of the direct model in this category, and is not a low-cost manufacturer. But Dell is first to ship latest technology, and offers greater value because it customises every order to individual specifications. For the business buyer Dell has developed processes to meet deeper customer needs before the sale (personalised information and prices through its Web-based Premier Pages) and after the sale (dedicated support and lifetime service promise through its telephone and online teams).

Similarly Gateway offers innovative value that Compaq cannot match in the home market. Gateway's Country stores allow neophytes to try its computers before they buy. Its distinctive and user-friendly customer support guides consumers, many of whom are spending their own money rather than a company's, through the experience of buying and installing new machines.

The PC market illustrates how process drives value innovation. Process enables a company to meet customer needs to their satisfaction and better. Continuous improvement in process enables a company to compete against new challengers and continuously surpass customer expectations.

While US airlines have arguably relied too much on mileage 'loyalty' programmes, Europeans have striven for new sources of value and created superior passenger experiences. For a time in the mid-1990s British Airways became the world's most profitable airline in fact, while its advertising promoted it more contentiously as the world's favourite. Under Colin Marshall BA set out to enhance the total customer experience, from planning and booking travel, through check-in, to arrival and the onward destination. BA invested in reservations systems, business departure and arrival lounges, superior seats, but above all in the quality of the processes and service delivered by its staff. More recently Virgin Atlantic has successfully grown both passenger volume and mindshare by creating distinctive experiences in which a wider range of entertainment and on-board services provide more fun for the jaded frequent traveller.

Digital technologies enable rapid leaps in process effectiveness and efficiency. Digital technology revolutionises process in two ways. Digital can automate and deliver existing services at a lower cost. 


\section{Processes and experiences will create brands}

\section{The relationship brand}

On the Web, Charles Schwab offers online advisory services as well as low-cost trades, undercutting high-cost Merrill Lynch brokers while competing with their professional advice. Secondly, digital technology can create new value from new processes, most dramatically from new software tools like Firefly and new market structures like eBay and Priceline that bring together buyers and sellers. The role of digital technology and the Web is to improve the performance and speed of process.

If the priority for the deployment of technology is to deepen the customer value proposition, product and price are no longer the basis for competition. Innovation strategy creates new value for customers from focus on (the apparently boring concept of) process, not product, to create tailored propositions and superior experiences for customers.

\section{Brand}

The new approach is to leverage superior processes and distinctive experiences in order to build ongoing and intimate relationships with customers. This is how the big brands of the future will be developed. Causation flows from process to experience to relationship to brand.

This is tantamount to turning the world of advertising on its head. In the past advertising created brands, but whereas advertising may be necessary in the future it will no longer be sufficient. Processes and experiences will create brands, and the character of the relationships they create with customers will define brands. Broadcast and print advertising will have two roles. Advertising will be a traffic builder, driving people to experience the brand (with direct response now playing a mainstream role). And advertising will continue to play a modest but necessary role in reflecting and reinforcing an established brand.

Brand is conventionally defined by function (what is distinctive), character (what is attractive) and emotion (what feelings are created with usage). But functional performance can easily be copied and matched by competition. And a brand character or emotion is no match for radical innovations in value, including but not limited to low prices. The definition of brand must now be deepened: from function to recognition (how the brand performs for me as an individual), from character to service (how the brand supports all my needs), and from emotion to belonging (how I am involved with the brand, and participate in its development). We can call the result a relationship brand.

Compelling brands are relationship brands, the result of a process of building intimate relationships with customers. A relationship is personal, and so a brand must recognise its valued customers and deliver to their personal needs. A relationship defines a commitment beyond the sale, and a brand must meet a customer's total service requirements in its chosen category and scope of activities. A relationship is active not passive, and requires the involvement of the customer. Involvement can take many forms: communication and feedback to improve the brand, information to guide better usage of the brand, advocacy and even active participation in its activities (eg attendance at events). 
Pearson

\author{
'Tell me and I'Il \\ forget, \\ Show me and I may \\ remember, \\ Involve me and I'II \\ understand.'
}

\section{Ancient Chinese proverb}

\section{Segment-specific marketing}

The new prospect is to use digital technology to involve customers and create sophisticated applications, information, services and support. Applications (eg online banking) enable customers to save time and do more. Information helps a customer extract more value from purchase or usage of a product category. Advisory services help a customer negotiate otherwise complex transactions. Support can be enhanced through real-time interaction with service databases and personnel, and even with other customers.

Relationship brands are most powerful when guided and even owned by their customers rather than by product makers and sellers.

If the relationship brand is managed with integrity (honouring the customer's trust), honesty (about the brand's proposition) and even humility (simply that the customer is usually right), advertising may be necessary but is no longer sufficient to build brands: the intimacy strategy develops compelling brands by building relationships with customers and so fulfilling an essential need in their life or business.

\section{Manage customer interactions across all media, channels and touch points}

This is an iterative optimisation process. Media, channels and touch points are selected based on customer preference and optimal results. Measurement of results and testing drives continuous improvement. Marketing is executed not through 'campaigns' that last for short periods of time, but through programmes targeted to customer segments and tracks created for individual customer types.

Segment-specific programme marketing will drive businesses towards a new media mix, in which not only does the role of advertising change but also communications become fully integrated, consistent and cohesive. Consistency means not just design, but that the brand is reflected in a set of experiences that are distinctive to the brand. Coherence means that these experiences are planned over time and reflect growing understanding of the customer. Segment-specific programmes are driven by data and rules based on data, and the critical success factor is the data and the data-based process for managing customers.

Segment-specific programme marketing will drive businesses towards multiple channels of distribution, enabling different customers to choose where, when and how they want to buy. Because different channels serve different customers, channel conflict can be managed and although there will be inevitable resistance to change - businesses can escape the thrall in which mass retailers and independent distributors have held them.

Segment-specific plans will encompass all touch points. In particular, sales and service (traditionally satrapies of operations) will be aligned and coordinated with communication and distribution (traditionally provinces of marketing).

Customer tracks are rules-driven processes that allocate to customers the media and messages they should receive in sequence. At the same time - very important - they communicate to all people in the business the information they require to add value to the customer relationship. 
Feedback leading to ...
Interaction with customers on the Web gathers information on behaviour (explicit choices, information accesses, purchases), preferences (implicit browsing patterns, pathways, sources) and characteristics (profiles and forms). Digital technology enables seamless transfer of the information by combining Internet with intranet (for staff and investors) and extranet (for partners and channels) - all capturing data to one database and accessing the rules in that database to guide decision making. The result is purposeful development of profitable customer relationships.

If serving customers is everyone's priority, and the basis for everyone's evaluation and - ultimately - earnings, marketing is too important to be left to marketers, and is not about media or advertising: effective marketing is guided by interactive strategy, and is the business design and operational management of customer experiences across all media, channels and touch points inside and outside the organisation.

\section{The operational model}

The learning from interaction with customers acts as a feedback loop to guide investment strategy, enables continuous improvement and completes the customer compass. The result should become a virtuous spiral of prosperity (see Figure 2), with increasing returns based on responsiveness to customer behaviour, competitive activity and marketplace dynamics.

The strategy is perhaps obvious, but there are critical changes to make before a business can operate customer relationship management. Delivering strategy requires a new operational model in which business is organised by customer segment not product line; technology is focused on enhancing the customer value proposition; customer feedback drives decision making throughout the organisation; and

Figure 2: The spiral of prosperity

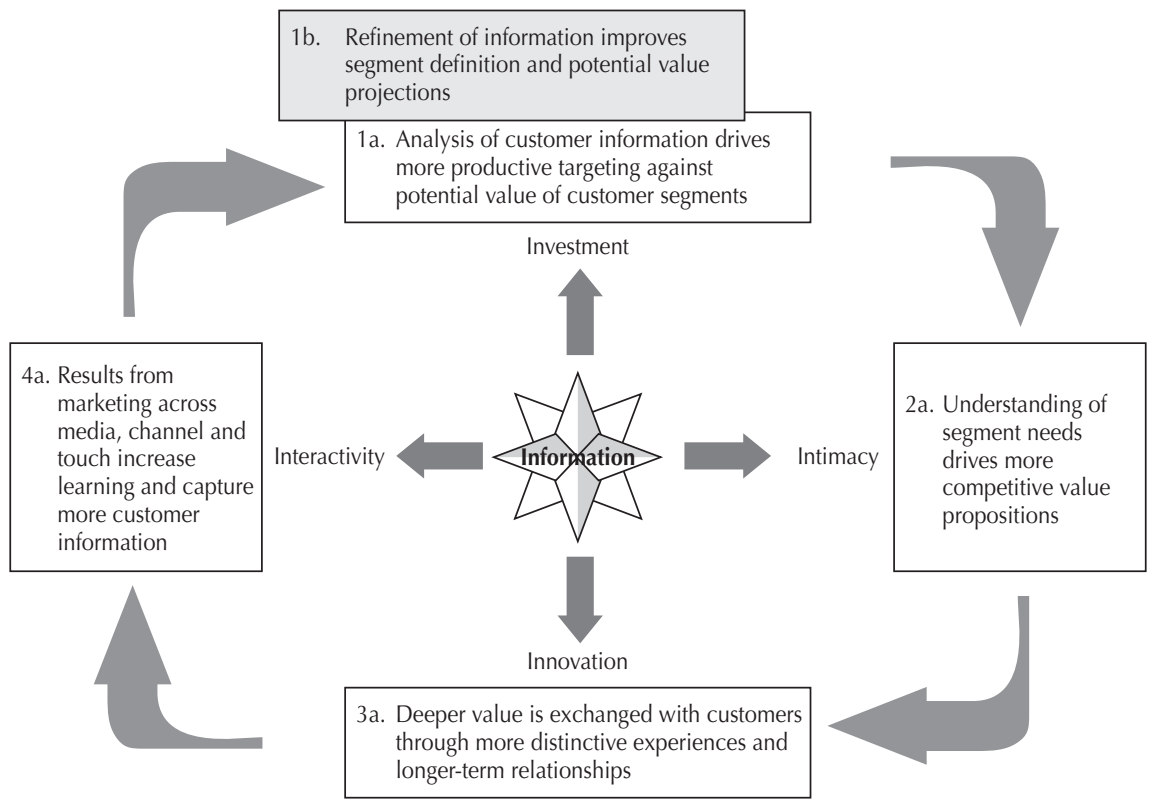




\section{Organisation by customer segment}

Figure 3: The new organisation

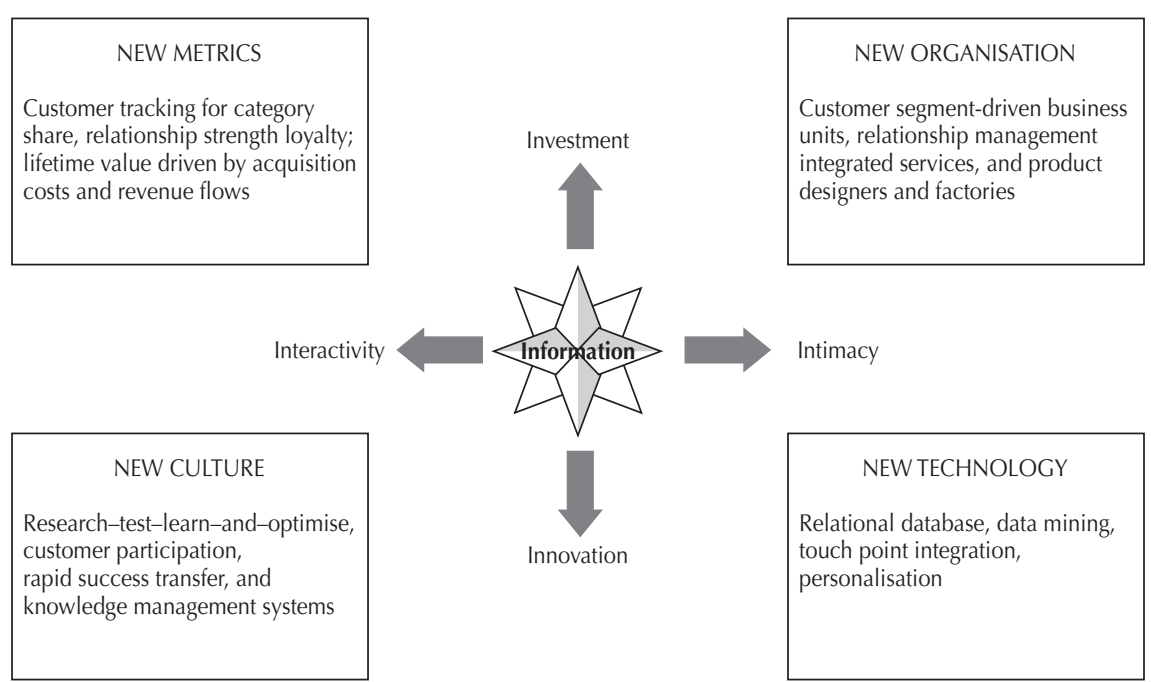

compensation and rewards are based on customer evaluation. This model demands new organisation, new technology, new culture and new metrics (see Figure 3).

The new organisation is based on customer segment. A futureorientated business should be organised by customer segment, not product line of business. This revolutionary concept does not contradict a current-period sales focus, and in fact will realise previously neglected sales opportunities and thus demonstrate increased revenue in the short as well as the long term.

The traditional organisation has functional units reporting to the CEO. Marketing may or may not be a board-level function, and is itself divided into silos. Further, sales, marketing and service are often managed within separate functions. Advertising, direct, promotions and public relations are different disciplines often working to different agendas with different tools. Product operations generally hold budgets, and the marketing roles are often staff with neither operational responsibility nor real accountability. And — astonishly — formal responsibility for the brand resides at a low level in the advertising function. (Figure 4 illustrates the traditional organisation.)

Figure 4: The traditional organisation

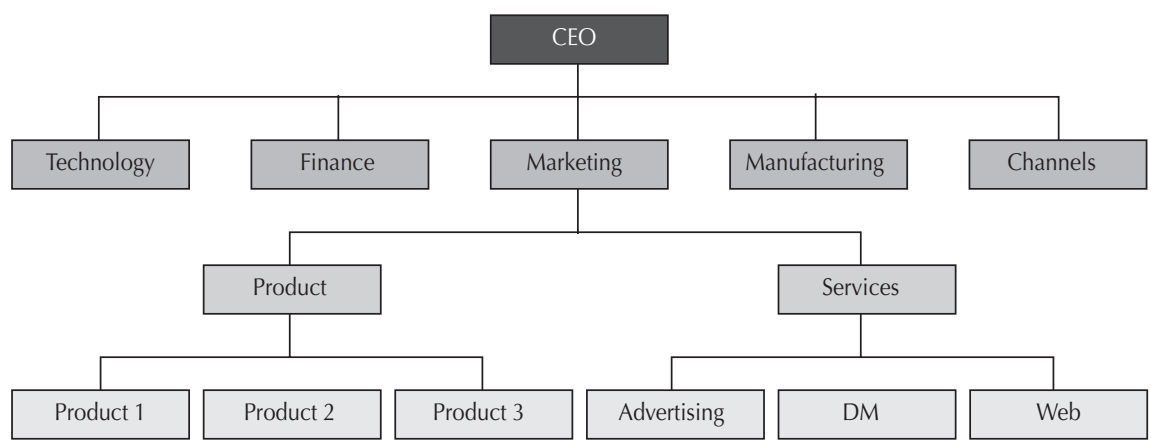


Figure 5: The new customer organisation

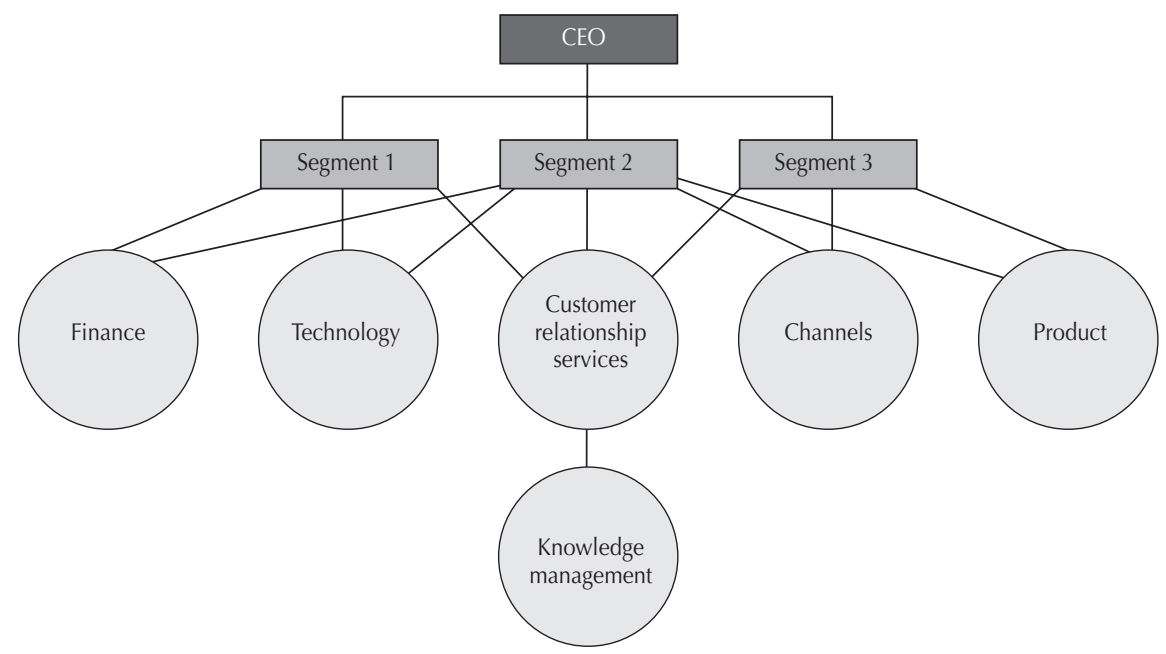

The new customer organisation has segment directors responsible for aspects of their business units, including full profit, loss, budgets and investment planning. All touch points, and in particular marketing and service, are integrated within a centre of excellence that we can call customer relationship services. Product functions become designers and manufacturers, or assemblers and aggregators from partners or alliances. Channels become operational managers and not business units. Finance and technology are the other principal support functions. (Figure 5 illustrates the new customer organisation.)

Most significantly, the responsibility for brand is located in its proper place, in the office of the chief executive. Each segment manager has a responsibility to reinforce and deepen the brand. All must present a unified set of values, with emphasis appropriate to their segment.

If the brand values do not resonate within the segment, a strategic possibility becomes to launch a new brand to compete successfully in the segment. This thinking has motivated significant new brand launches in financial services (Midland's First Direct, Prudential's Egg, BancOne's WingspanBank are examples). In this category younger consumers do not relate well to established banks. Another category with new brand launches has been travel (British Airways' low-cost European airline Go, for example).

The new technology is customer-driven. The drive for technology

'You can wire yourself up until you are blue in the face (and broke) - but in the end it's a people game.'

\section{Tom Peters} must be to capture customer information and make it accessible where it adds the greatest value, at the customer interface. The elements of customer-driven technology are now available: relational databases and data mining are now mature technologies. But the emphasis now is on integration: enterprise-wide applications for Web integration, computer-telephony integration and other remote-touch-point integration from direct mail to salesforce automation. Integrated, enterprise-wide applications enable personalisation of messaging and service at all contact points. 


\section{'May you live in interesting times.' \\ Ancient Chinese proverb}

\section{'It is not the strongest of the species that survive, not the most intelligent, but the ones most responsive to change.'}

Charles Darwin
Technology, of course, only delivers information. The new culture is based on knowledge and on the sharing of information. When information is widely shared, learning is rapidly transferred, delivering a measurable increase in productivity. The character of decision making becomes more factual and even more democratic. Senior management listens to customer-facing staff, and not just the other way around. Investments are based not on opinions, prejudices or even accepted truths but on what works for customers. Processes drive a test-learn-optimise culture.

When knowledge is rapidly shared across the organisation, especially in global businesses, success travels fast, with learning from one market quickly transferred, adapted and applied to another. Testing is continuous, and learning helps conceive new strategies and refine ageing ones. The business is always listening to and involving the customer to stay ahead of their needs and competitive moves. Included in this new culture will be customer boards or panels motivating the direct involvement of representative customers.

The new metrics are customer-based. With the profit and loss based on customer segment, staff can more closely relate their performance to results. With new forms of research tracking true customer loyalty (the propensity to buy from the brand in the face of competition), staff can immediately understand not only what the customer has previously bought but what the customer will potentially buy in the future - and from whom.

The new metrics are the foundation of the new business model. Analysis of potential value drives strategy. The author has rarely seen any business that could not realise more value from targeted customer segments, if only it became focused, nor any business that could not realise continuing improvements, if only it tracked its customers, their behaviour and feedback.

In conclusion, customer relationship management is an enterprise-wide strategy for competing in the new information economy. But without radical change in organisation, technology, culture and metrics companies will fail to realise the potential of CRM. 